\title{
Down-regulation of miRNA-30c predicts poor prognosis in Colorectal Cancer patients
}

\author{
Liu Bin, Meng Zhang*, Liu Lixia, Zang Aimin, Yang Hua, Shang Yanhong, \\ Yang Yang, Gao Feng, Liu Bo, Zhang Yonggang, Tian Huiping \\ The Affiliated Hospital of Hebei University, Baoding, China
}

\begin{abstract} teristics and prognosis were statistically analyzed. predictor for poor prognosis. treatment measures.

\section{Introduction}

Colorectal carcinoma (CRC) is one of the most common cancer-related mortalities worldwide [1]. Although several kinds of advances in tumor diagnosis and treatment have been developed recently, CRC patients still have poor prognosis [2]. To date, as the reliable biomarkers for clinical diagnosis and prognosis are still lacking, there is a critical need to explore novel markers for CRC.
\end{abstract}

Background: MiRNA-30c was a tumor suppressor in several human cancers, however, its association with clinicopathological features and prognosis in colorectal cancer (CRC) is unclear.

Materials and Methods: The expression level of miRNA-30c in 192 pairs of colorectal cancer and adjacent normal tissues was detected by Quantitative RT-PCR, the association between miRNA-30c expression and clinical charac-

Results: miRNA-30c was significantly lower in CRC tissues specimens compared with matched normal adjacent tissue $(P<0.001)$. MiRNA-30c was positively correlated with tumor size $(P=0.012)$, TMN stage $(P=0.002)$ and lymph node metastasis $(P=0.004)$. The univariate analysis showed $C R C$ patients with low miRNA-30c had distinctly shorter overall survival $(P<0.001)$ than patients with high miRNA-30c expression level. The multivariate analysis was performed and informed that low miRNA-30c expression $(P<0.001)$ might be an independent prognostic

Conclusion: miRNA-30c could predict the prognosis of colorectal cancer which is helpful to choose reasonable

Keywords: Colorectal cancer, miRNA-30c, Quantitative RT-PCR, Overall survival.

Received: 07th June 2016; Accepted: 06 ${ }^{\text {th }}$ October 2016; Published: 10 ${ }^{\text {th }}$ October 2016.

MicroRNAs (miRNAs) are short, and noncoding RNAs of 18-22 nucleotides in length which can alter gene expression by targeting 3'-untranslated regions [3]. More and more evidence informed that aberrant expression of miRNAs is correlated with cancer, including CRC [4]. miRNAs can serve as either oncogenes or tumor suppressors $[5,6]$. A recent study showed that the expression level of miRNA-32 was upregulated in CRC tissues. The over-expression of

* Corresponding author: Meng Zhang, The Affiliated Hospital of Hebei University, Baoding, China, e-mail: z15175292891@163.com 
miRNA-32 was strongly associated with tumor stage, distal metastases and poor prognoses [7]. miRNA-135a are upregulated in CRC, and this was associated with a reduction in adenomatous polyposis coli (APC) gene expression [8]. Michael et al. reported that over-expression of miRNA-143 associated with the poor prognosis of patients with colorectal carcinoma [9]. Furthermore, miRNA-378 and miRNA-378a-5p expressions were potential unfavorable prognostic factors for colorectal carcinoma $[10,11]$. That evidence informed that miRNAs may be help for a potential application and therapeutic application in colorectal carcinoma.

Numerous researches have informed that the deregulation of miRNA-30c play an important role in different tumors, including endometrial cancer, liver cancer, and colorectal cancer [12-13]. Futhermore, low expression of miRNA-30c is associated with poor prognosis in prostate carcinoma [14]. However, the role of low expression of miRNA-30c in colorectal cancer has not been clearly understood. The aim of our study is to compare the expression level of miRNA-30c in CRC and noncancerous issues, to find the association between miRNA-30c and different TNM stage and to compare the survival time of CRC patients with high miRNA-30c or low miRNA-30c to explore the prognostic value of miRNA-30c in colorectal cancer.

\section{Material and methods}

\section{Samples}

CRC specimens were obtained from patients with a diagnosis of primary colorectal cancer who underwent surgery at the Affiliated Hospital of Hebei University between 2007 and 2014. The inclusion criteria are as follows: all patients were confirmed by pathological examination results. Histological type and tumor-node-metastasis
(TNM) classifications were made according to the criteria of UICC/AJCC (International union against cancer/American joint committee on cancer) TNM classification system [15]; No patients received any preoperative treatment (such as radiotherapy and chemotherapy except preoperative radiotherapy used for rectal cancer patients) before surgery excision or patients received last treatment 4 weeks before. All tissue samples were immediately frozen in liquid nitrogen and stored at $-80^{\circ} \mathrm{C}$ until use. Detailed information and clinicopathological characteristics are summarized in Table 1. Overall survival (OS) time was calculated from the time of the primary surgery to death. This study was approved by the Ethics Committee of the Affiliated Hospital of Hebei University, and all participants provided informed consent.

\section{RNA isolation and quantitative real-time PCR (qRT-PCR)}

Trizol reagent (Invitrogen, Carlsbad, CA, USA) was used to extract total RNA from frozen CRC tissues according to the manufacturer's instructions. The flow of extracting all RNA was performed under RNase-free conditions. The Prime Script TM RT reagent Kit (TaKaRa Company, Dalian, China) was used to synthesize the cDNA according to the manufacturer's instructions. A 7500 real-time PCR System (Applied Biosystems Company, Waltham, USA) was used to perform real-time PCR following the manufacturer's protocol. The condition for determining miRNAs was as follows: $52^{\circ} \mathrm{C}$ for $3 \mathrm{~min}, 96^{\circ} \mathrm{C}$ for $8 \mathrm{~min}, 45$ cycles of $96^{\circ} \mathrm{C}$ for $20 \mathrm{~s}$, and $65^{\circ} \mathrm{C}$ for 1 min. U6 small nuclear RNA (snRNA) was used as an internal control.

\section{Statistics}

All computations were performed using the SPSS 17.0 software package (SPSS, Chicago, 
IL, USA). The expression level of miRNA-30c was determined for associations with clinicopathological characteristics using the student's t-test or chi-square test. The KaplanMeier method was used to calculate overall survival. Log-rank tests were used to compare differences between groups. Multivariate analysis of the prognostic parameters was performed using Cox regression model. $\mathrm{P}<0.05$ was considered to be statistically significant.

\section{Results}

As shown in Table 1, 192 patients were included in this research where 89 were less than 55 years old, of which 103 were male.

The expression of miRNA-30c was significantly down-regulated in CRC tissues compared to noncancerous tissues $(\mathrm{P}<0.001$, shown in Figure 1).

The median of miRNA-30c expression in all 192 patients was used as a cut-off. Furthermore, we divided the patients into two groups. As shown in Table 1, the expression level of

Table 1. Correlation between miRNA-30c expression and clinicopathological features of colorectal cancer cases

\begin{tabular}{|c|c|c|c|c|}
\hline \multirow{2}{*}{ Variables } & \multirow{2}{*}{ Cases $(n=192)$} & \multicolumn{2}{|c|}{ miRNA-30c expression level } & \multirow{2}{*}{ Pvalue } \\
\hline & & Low(\%) & $\operatorname{High}(\%)$ & \\
\hline$\overline{\text { Age (years) }}$ & & & & 0.247 \\
\hline$<55$ & 89 & 53.93 & 46.07 & \\
\hline$\geq 55$ & 103 & 44.66 & 55.34 & \\
\hline Gender & & & & 0.902 \\
\hline Male & 103 & 48.54 & 51.46 & \\
\hline Female & 89 & 49.44 & 50.56 & \\
\hline Tumor size $(\mathrm{cm})$ & & & & $0.012 *$ \\
\hline$<5$ & 99 & 40.40 & 59.60 & \\
\hline$\geq 5$ & 94 & 58.51 & 41.49 & \\
\hline Histology/differentiation & & & & 0.195 \\
\hline Well + moderate & 97 & 44.33 & 55.67 & \\
\hline Poor & 95 & 53.68 & 46.32 & \\
\hline Depth of invasion & & & & 0.848 \\
\hline $\mathrm{T} 1+\mathrm{T} 2$ & 81 & 48.15 & 51.85 & \\
\hline $\mathrm{T} 3+\mathrm{T} 4$ & 111 & 49.55 & 50.44 & \\
\hline Lymph node metastasis & & & & $0.004 * *$ \\
\hline Negative & 77 & 33.77 & 66.23 & \\
\hline Positive & 105 & 52.38 & 47.62 & \\
\hline Stage of regional lymph node & & & & $0.002 * *$ \\
\hline I & 34 & 32.35 & 67.65 & \\
\hline II & 46 & 39.13 & 60.87 & \\
\hline III & 112 & 58.04 & 41.96 & \\
\hline
\end{tabular}

Note: $* P<0.05,{ }^{* *} P<0.01$ 


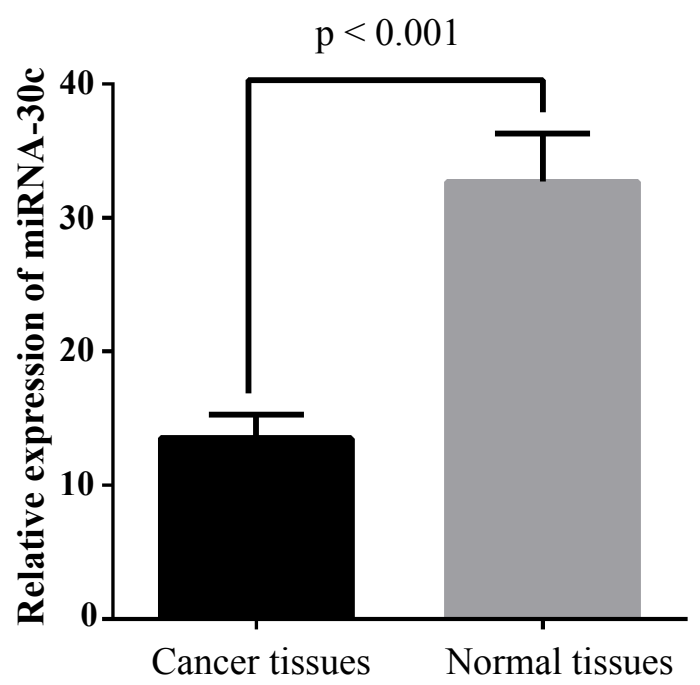

Figure 1. The level of miRNA-30c in cancer tissues is lower than that in corresponding adjacent tissues.

NOTE: The 2- $\triangle C t$ method was used to detect miRNA-30c expression levels.

low miRNA-30c was closely correlated with large tumor size (tumor size $>5 \mathrm{~cm}$ was considered as large [16] $(\mathrm{P}=0.012)$, advanced clinical stage (from I to III) of regional lymph node $(\mathrm{P}=0.002)$ and positive lymph node metastasis $(\mathrm{P}=0.004)$. However, there were no significant

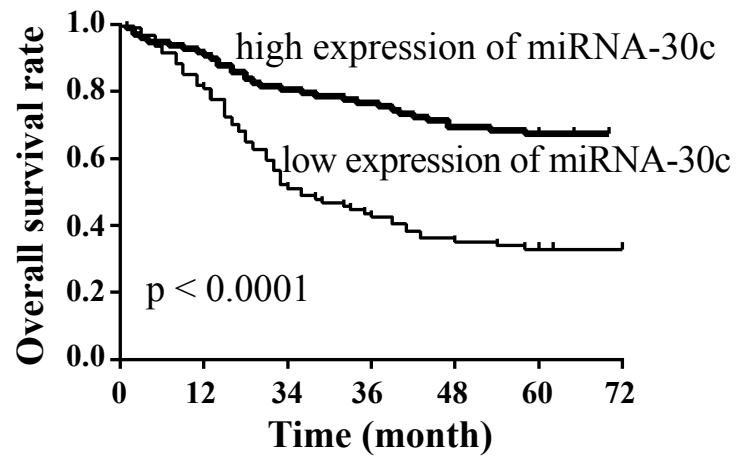

Figure 2. The Kaplan-Meier postoperative survival curve for patterns of colorectal cancer patients and miRNA-30c expression.

NOTE: Patients in low-miRNA-30c group had significantly poorer prognosis than those in highmiRNA-30c group $(P<0.0001$, log-rank test $)$.

differences between miRNA-30c expression, patients' age, gender, tumor differentiation, and depth of invasion.

Patients with low miRNA-30c expression had a significantly shorter survival time than those with high miRNA-30c expression $(\mathrm{P}<0.0001)$ (Figure 2). The results of univariate and multivariate analyses for overall survival are shown in Table 2. Univariate analysis showed that tumor size $(\mathrm{cm})$, depth of invasion, lymph

Table 2. Univariate and multivariate analyses of prognostic factors in colorectal cancer

\begin{tabular}{lcccccc}
\hline \multirow{2}{*}{ Variable } & \multicolumn{3}{c}{ Univariate analysis } & \multicolumn{3}{c}{ Multivariate analysis } \\
\cline { 2 - 7 } & HR & $\mathbf{9 5 \%}$ CI & $\boldsymbol{P}$ & HR & $\mathbf{9 5 \%}$ CI & $\boldsymbol{P}$ \\
\hline Age (years) & 1.529 & $0.721-3.762$ & 0.256 & - & - & - \\
\hline Gender (male) & 1.241 & $0.651-2.891$ & 0.661 & - & - & - \\
\hline Histological grading & 1.801 & $0.881-3.452$ & 0.239 & - & - & - \\
\hline Tumor size (cm) & 2.818 & $1.321-5.819$ & $0.032^{*}$ & 2.518 & $0.881-4.732$ & 0.091 \\
\hline Depth of invasion & 2.921 & $1.212-5.541$ & $0.029^{*}$ & 1.771 & $0.762-3.549$ & 0.337 \\
\hline Lymph node metastasis & 5.919 & $2.031-9.733$ & $0.003^{* *}$ & 5.324 & $2.238-11.067$ & $0.004^{* *}$ \\
\hline Stage of regional lymph node & 3.117 & $1.328-7.154$ & $0.023^{*}$ & 5.488 & $2.231-11.225$ & $0.002^{* *}$ \\
\hline miRNA-30c level & 3.441 & $1.552-8.341$ & $0.008^{* *}$ & 2.561 & $1.221-5.651$ & $0.031^{*}$ \\
\hline
\end{tabular}

NOTE: $* P<0.05$, ** $P<0.01$ 
node metastasis, stage of regional lymph node and miRNA-30c level were risk factors of survival time of CRC patients. Multivariate analysis revealed that miRNA-30c expression $(\mathrm{P}=0.031)$, lymph node metastasis $(\mathrm{P}=0.004)$ and advanced clinical stage of regional lymph node $(\mathrm{P}=0.002)$ were independent and significant prognostic factors for survival (Table 2).

\section{Discussion}

Over the past decade, more and more evidence showed that miRNAs are involved in the initiation, progression, and metastasis of CRC [17]. As a consequence, elucidating new prognosis factors is necessary as present reports cannot explain all issues. In our study, the data showed that miRNA-30c expression was significantly decreased in CRC tissues compared to adjacent normal tissues. Furthermore, we found that low expression of miRNA-30c showed significant association with aggressive clinicopathological features. Moreover, Kaplan-Meier survival analysis informed that decreased expression of miRNA-30c was associated with the reduced overall survival of CRC patients. We carried out the multivariate analysis and confirmed that miRNA-30c was an independent predictor of overall survival. Our finding showed that miRNA-30c might be used as a valuable prognostic indicator. Our results indicate that low expression of miRNA-30c may have prognostic relevance in CRC patients.

Many studies reported that miRNA-30c may function as tumor suppressor or tumor promoter. Recently, it was reported that human miRNA-30c was down-regulated in non-small cell lung cancer (NSCLC) and breast cancer $[18,19]$, this informed that miRNA-30c functioned as a tumor suppressor. Quintavalle et al. reported that miRNA-30c could suppress apoptosis of lung cancer cells [20]. Besides, miRNA-30b may play a biological role in breast cancer through targeting cyclin E2 [21]. Similarly, Ling et al proved miRNA-30c as an independent biochemical recurrence predictor for prostate cancer. Taken together, all the results informed that miRNA-30c may play an important effect in cancer progression.

Our interest is the association between miRNA-30c and colorectal cancer. Recently, Zhang et al, reported that the expression level of miRNA-30c was decreased in both colon cancer cell lines and CRC specimens of patients. Furthermore, they found that miRNA-30c suppress cancer cell growth, migration through targeting ADAM19 in colorectal cancer. At present, there is no research report about the prognostic value between miRNA-30c and colorectal cancer, so we have done some research in this area.

In summary, our results show that miRNA-30c was down-regulated in CRC tissues. Moreover, we found down-regulation of miRNA-30c was closely associated with aggressive clinicopathological features and worse prognosis. However, there were still some limitations in this research. First of all, few participants were included in this research. Second, all included participants were from the affiliated hospital of Hebei university rather than a multi center research area. Third, this paper did not include the mechanisms research. As a consequence, further studies based on a large number of participants and multi centers are needed on the detailed biological mechanisms and biological functions of miRNA-30c.

\section{Conflict of interest}

There was no conflict in this work.

\section{Acknowledgement}

None. 


\section{Abbreviations}

$$
\begin{array}{ll}
\text { CRC } & =\text { Colorectal carcinoma } \\
\text { miRNAs } & =\text { MicroRNAs } \\
\text { APC } & =\text { adenomatous polyposis coli } \\
\text { TNM } & =\text { Tumor-node-metastasis } \\
\text { qRT-PCR } & =\text { Quantitative real-time PCR } \\
\text { SnRNA } & =\text { Small nuclear RNA } \\
\text { OS } & =\text { Overall surviva } \\
\text { NSCLC } & =\text { Non-small cell lung cancer }
\end{array}
$$

\section{References}

1. Parkin DDM. Global cancer statistics in the year 2000. Lancet Oncol. 2001;2(9):533-43. DOI: 10.1016/S14702045(01)00486-7.

2. $\mathrm{Ng} \mathrm{SC}$, Wong SH. Colorectal cancer screening in Asia. $\mathrm{Br}$ Med Bull. 2013;105(1):29-42. DOI: 10.1093/bmb/lds040.

3. Lagos-Quintana M, Rauhut R, Lendeckel W, Tuschl T. Identification of novel genes coding for small expressed RNAs. Science. 2001;294(5543):853-8. DOI: 10.1126/science. 1064921 .

4. Liu M, Chen H. The role of microRNAs in colorectal cancerr. J Genet Genomics. 2010;37(6):347-58. DOI: 10.1016/S1673-8527(09)60053-9.

5. Wang H, An H, Wang B, Liao Q, Li W. miR-133a represses tumour growth and metastasis in colorectal cancer by targeting LIM and SH3 protein 1 and inhibiting the MAPK pathway. Eur J Cancer. 2013;49(18):392435. DOI: $10.1016 /$ j.ejca.2013.07.149.

6. Wu ZS, Wang CQ, Ru X, Xue L, Shan Y, Yang XQ, et al. Loss of miR-133a expression associated with poor survival of breast cancer and restoration of miR133a expression inhibited breast cancer cell growth and invasion. Bmc Cancer. 2012;12(1):1-10. DOI: 10.1186/1471-2407-12-51.

7. Wu W, Yang P, Feng X, Wang H, Qiu Y, Tian T, et al. The relationship between and clinical significance of MicroRNA-32 and phosphatase and tensin homologue expression in colorectal cancer. Genes Chromosomes Cancer. 2013;52(12):1133-40. DOI: 10.1002/gcc.22108.

8. Nagel R, Le SC, Diosdado B, Van dWM, Oude Vrielink JA, Bolijn A, et al. Regulation of the adenomatous polyposis coli gene by the miR-135 family in colorectal cancer. Cancer Res. 2008;68(14):5795-802. DOI: 10.1158/0008-5472.CAN-08-0951.
9. O'Connor SM, Young GP, Van HP, N G, James RJ, Michael MZ. Reduced accumulation of specific MicroRNAs colorectal neoplasia; colorectal neoplasia. Oncol \& Carcinog. 2003.

10. Zhang GJ, Zhou H, Xiao HX, Li Y, Zhou T. MiR378 is an independent prognostic factor and inhibits cell growth and invasion in colorectal cancer. Bmc Cancer. 2014;14(6):109. DOI: 10.1186/1471-240714-109.

11. Li H, Dai S, Zhen T, Shi H, Zhang F, Yang Y, et al. Clinical and biological significance of miR-378a$3 p$ and miR-378a-5p in colorectal cancer. Eur J Cancer. 2014;50(6):1207-21. DOI: 10.1016/j. ejca.2013.12.010.

12. Rodríguez-González FG, Sieuwerts AM, Smid M, Look MP, Gelder MV, Weerd VD, et al. MicroRNA30c expression level is an independent predictor of clinical benefit of endocrine therapy in advanced estrogen receptor positive breast cancer. Breast Cancer Res Treat. 2011;127(1):43-51. DOI: 10.1007/s10549010-0940-x.

13. Budhu A, Jia H-L, Forgues M, Liu CG, Goldstein D, Lam A, et al. Identification of metastasis-related microRNAs in hepatocellular carcinoma. Hepatology. 2008;47(3):897-907. DOI: 10.1002/hep.22160.

14. Huang Z, Long Z, Yi X, Yu X. Diagnostic and prognostic values of tissue hsa-miR-30c and hsa-miR-203 in prostate carcinoma. Tumour Biol. 2015:1-7. DOI: 10.1007/s13277-015-4262-9.

15. Edge SB, Byrd DR, Compton CC, Fritz AG, Greene FL, Trotti A, editors. AJCC cancer staging manual (7th ed). New York, NY: Springer; 2010.

16. Huang B, Feng Y, Zhu L, Xu T, Huang L, Cai G. Smaller tumor size is associated with poor survival in stage II colon cancer: An analysis of 7,719 patients in the SEER database. Int J Surg.2016; 33(Pt A):157-63. DOI: 10.1016/j.ijsu.2016.07.073.

17. Amirkhah R, Farazmand A, Irfanmaqsood M, Wolkenhauer O, Wolkenhauer O, Schmitz U. The role of microRNAs in the resistance to colorectal cancer treatments. Cell Mol Biol. 2015;61(6):17-23. DOI: 10.14715/cmb/2015.61.6.4.

18. Peng G, Yin Z, Li X, Wei W, Zhou B. Meta-analysis of human lung cancer microRNA expression profiling studies comparing cancer tissues with normal tissues. J Exp Clin Cancer Res. 2012;31(1):1-8. DOI: 10.1186/1756-9966-31-54. 
19. Tanic M, Yanowsky K, Rodriguezantona C, Andrés R, Márquezrodas I, Osorio A, et al. Deregulated miRNAs in hereditary breast cancer revealed a role for miR-30c in regulating KRAS oncogene. Plos One. 2012;7(6). DOI: $10.1371 /$ journal.pone.0038847.

20. Quintavalle C, Donnarumma E, Iaboni M, Roscigno G, Garofalo M, Romano G, et al. Effect of miR-21 and $\mathrm{miR}-30 \mathrm{~b} / \mathrm{c}$ on TRAIL-induced apoptosis in glioma cells. Oncogene. 2012;31(34):4001-8. DOI: 10.1038/ onc.2012.410.

21. Ichikawa T, Sato F, Terasawa K, Tsuchiya S, Toi M, Tsujimoto $\mathrm{G}$, et al. Trastuzumab produces therapeutic actions by upregulating miR-26a and miR-30b in breast cancer cells. Plos One. 2012;7(2):e31422. DOI: 10.1371/journal.pone.0031422. 